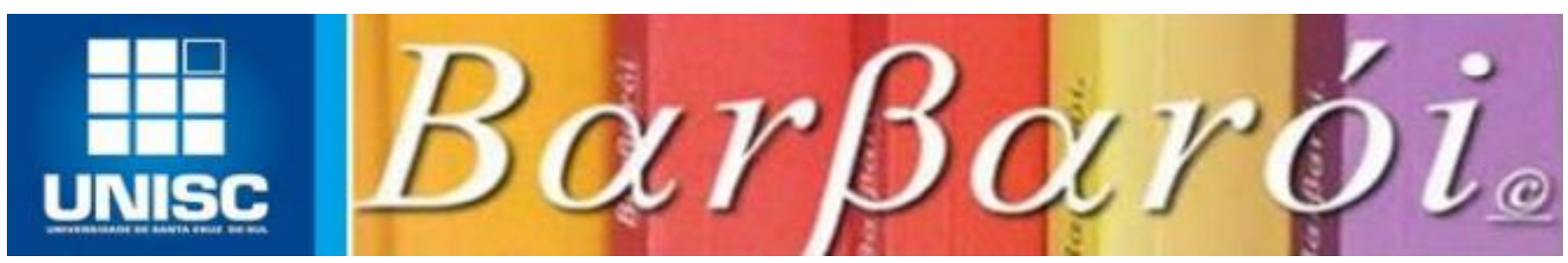

\title{
A ESCOLA E OS POBRES DO SERTÃO NORDESTINO DO BRASIL: CONSIDERAÇÕES ETNOGRÁFICAS A PARTIR DE CATINGUEIRA - PB ${ }^{1}$
}

DOI: http://dx.doi.org/10.17058/barbaroi.v2i52.11460

\author{
Antonio Luiz da Silva ${ }^{2}$ \\ Universidade Federal do Rio Grande do Norte - UFRN - Brasil
}

\section{RESUMO}

Neste artigo, resultado de uma investigação etnográfica realizada em Catingueira - PB, objetiva-se refletir sobre a importância que a escola foi conquistando através das gerações no Sertão nordestino. Indicar-se-á que a escola se apresenta hoje como uma das instituições mais valorizadas pelas famílias pobres sertanejas. Mostrar-se-á que o sonho de uma formação escolar esteve, para muitas gerações, comprimido entre a utopia e a realidade da penúria material, do trabalho precoce, do abandono político, do sofrimento, da migração etc. Será ainda apontado que a escola sertaneja vem se modificando, de dentro para fora e de fora para dentro, em decorrência de ações trazidas pelas políticas públicas. Conclui-se que mesmo contendo componentes ainda sombrios, como descasos para com trabalhadores(as) e para com os equipamentos públicos da educação, a escola sertaneja contém fragmentos de esperanças, se firmando como contributo para a quebra do ciclo de miserabilidade que têm marcado aquela cidade e a região.

Palavras-chave: Escola; Sertão; Etnografia.

\section{A educação para os pobres: questões introdutórias ${ }^{3}$}

Do Brasil Colônia, passando pelo Império e até o início da República, para não estender a triste análise um pouco mais para frente, com um percentual alto de certeza, podese afirmar que nenhuma estratégia política, estratégia de governo de eficácia real, foi elaborada no sentido de garantir alguma motivação para que os filhos das camadas mais empobrecidas pudessem estudar e se formar. A estrutura social brasileira, desde sua nascença,

\footnotetext{
${ }^{1}$ Uma palavra de agradecimento ao Herculano Ricardo Campos (professor do PPGPsi/UFRN) pelas discussões e orientações durante o processo que resultou todo esse trabalho e a própria conclusão do doutorado. Agradecimento especial à Flavia Ferreira Pires (Professora do PPGA/UFPB) pela apresentação ao campo de pesquisa ainda em 2011 e pela orientação no mestrado. Gratidão à Patrícia Oliveira S. dos Santos (Doutoranda do PPGCS/UFCG) pela leitura cuidadosa desta versão.

${ }^{2}$ Realizei Formação de Psicólogo e Licenciatura Plena em Psicologia pela Universidade Estadual da Paraíba UEPB. Fiz uma especialização em Gestão Escolar pela Faculdade Kúrios do Ceará - FAK/CE. Estudei Mestrado em Antropologia na Universidade Federal da Paraíba - UFPB. Completei o Doutorando em Psicologia na Universidade Federal do Rio Grande do Norte - UFRN. Sou membro do grupo de pesquisa CRIAS - Criança, Sociedade e Cultura da UFPB. tonlusi@ hotmail.com

${ }^{3}$ Parte do material desse artigo compõe um capítulo de minha tese de doutorado, defendida em 2018, na Universidade Federal do Rio Grande do Norte - UFRN.
} 
já sabia previamente onde colocar o homem, a mulher, o jovem, a moça, a criança, os ricos e os pobres, lógica que parecia servir para toda e qualquer instituição da sociedade. Para Castro (2013, p. 40): "Na grande família colonial, fundada na estrutura da propriedade rural, os lugares de cada um estavam dispostos hierarquicamente conforme sua importância, todos sob a figura do poderoso senhor das terras”. Naquela ambiência fixada, o espaço de cada pessoa estava dado antecipadamente, pelo 'tom' da pele, pela condição de gênero, pela classe econômica, pela ordem geracional, pela origem social, antes mesmo do nascimento de cada indivíduo.

Para os pobres, numa sociedade, como a acima destacada, para que estudar? Para eles, por muito tempo na história nacional, estudar, quando muito, era a exceção e não a regra, estivessem eles na beira mar ou no Sertão; com maior dificuldade, claro, se estivessem no Sertão. Para muitas gerações de famílias pobres saber ler e escrever uma carta já era mais do que o suficiente. E para um certo grupo social, para as elites tradicionais, políticas e econômicas dominantes, salvando-se um ou outro exemplar, era importante que assim fosse e que assim permanecesse por mais tempo possível. Aliás, pensa-se que vale também para Brasil e para o território sertanejo a luz trazida pela observação sagaz de Mézáros (2012, p. 69): "Na concepção de educação há muito dominante, os governantes e os governados, assim como os educacionalmente privilegiados [...] e aqueles que têm de ser educados, aparecem em compartimentos separados, quase estanques”. Assim, mesmo que a criança do pobre e a do rico brincassem juntas na infância, separavam-se para sempre quando uma delas partia para o colégio interno. No universo social das classes, de um lado estavam e deveriam permanecer os privilegiados; do outro, estava o resto, a sobra condenada à condição de mão de obra explorável e iletrada. Por isso, é fato que a escola formal, historicamente e por longos séculos, aqui e alhures, teve sim valor menor para as camadas mais empobrecidas. Mas a essa percepção faz-se necessário acrescentar que esse pouco valor não deve, em hipótese alguma, ser imputado às camadas mais empobrecidas. É preciso dizer que assim era não por elas, e sim pelas condições sociais, políticas, econômicas e materiais a que estiveram desde sempre submetidas. Afinal de contas, ninguém pode ser pobre e iletrado apenas porque quer.

De qualquer modo, se quer chamar a atenção para um fato contraditório inscrito naquilo que diz respeito à educação nacional, especialmente quando pensada a partir da inclusão dos mais pobres. Sobretudo, dentro das que sempre detiveram o comando político e econômico da nação, está claro que algumas camadas da sociedade nacional não se interessavam pela escolarização dos mais empobrecidos, criando para eles políticas públicas efetivas para a sua 
inclusão social. Contudo, e aqui está a sutil contradição, Campos, Leal e Facci (2016) constataram que desde 1824 dois incisos do artigo 171 da Constituição Imperial já destacavam direitos universais à educação no país. "O primeiro trata da garantia da "instrução primária a todos os cidadãos", e o outro afirma o compromisso institucional com "colégios e universidades" (BRASIL, 1824)" (CAMPOS, LEAL \& FACCI, 2016, p. 207). É, portanto, importante se pensar que nem todos os que estavam no comando político e econômico da nação se orientavam pelos mesmos ideários. Talvez uma pequena exceção, nas elites políticas e econômicas, estaria fazendo alguma 'balbúrdia' intelectual no intento de inserir os mais empobrecidos nos 'privilégios' da nação. Mas, será que caberiam todos os pobres, todos os índios e todos os negros do território nacional nessa rubrica constitucional?

Lembra-se, contudo, que a partir do quadro dramático acima pintado não se está defendendo que se conseguiu uma promoção generalizada de embrutecimento do gênero humano nas camadas mais empobrecidas. Para qualquer estudioso da psicologia diferencial é razoável reconhecer que a inteligência pode sim florescer, inclusive, nas mais absurdas contradições sociais. Assim como não ter estudado não resultava necessariamente numa bruteza cognitiva, não ter tido acesso à escola não significava não ter saber. Para o Brasil e para as suas diferentes regiões, inclui-se aqui a vastidão sertaneja, dada a conjuntura social, as heranças culturais e morais eram repassadas através do contato direto das gerações mais novas com as gerações mais velhas. E, por conta da distância do elemento escolar e profissionalizante, fazendo o trabalho da professora, era a mãe quem ensinava como se fazia uma galinha à cabidela, um sarapatel, um bolo na palha da bananeira, uma tapioca, uma feijoada, um cozido, como eram lavadas as vísceras de um animal ou como se alvejava uma roupa antes de ser posta no arame para secar. Cabia ao pai ensinar como se trabalhava no roçado, se brocava, encoivarava e arava a terra, como se amolavam as ferramentas, se cortava com a foice ou com o machado, como se montava em um cavalo, como se fazia uma cangalha, como se desatolava um boi ou se realizava o parto de um bezerro. Era o vizinho ou o padrinho quem ensinava a fazer uma sela, a consertar o sapado, a cultivar o pasto. Para que saber mais válido?

No Brasil, embora nem sempre respeitado como prática includente, o acesso à escola e à educação formal como direito tem sido um debate antigo (CAMPOS, LEAL \& FACCI, 2016). Contudo, a valorização que contemporaneamente a escola e a educação vêm alcançando firmou-se a partir dos primórdios do século passado. E a tentativa de universalização da escola como direito, direito estendido de forma mais efetiva aos mais 
pobres, parece ser ainda mais recente. Ao dizer isso, pensa-se especificamente na redemocratização nacional, na Constituição Federal de 1988, no Estatuto da Criança e do Adolescente - ECA, de 1990 e na Lei de Diretrizes e Bases da Educação Nacional - LDB, de 1996, sem negar, contudo, a existência e a importância de outros marcadores históricos anteriores, nomes e lutas pela expansão concreta da educação nacional. Assume-se que para realidade da sociedade nacional contemporânea, a educação escolar tem se tornado não apenas uma necessidade, mas também uma unanimidade. Como afirmou o grande Paulo Freire (2000, p. 67): "Se a educação sozinha não transforma a sociedade, sem ela tampouco a sociedade muda". E assim, também na compreensão dos mais pobres, ela tem se transformado no contrário daquilo que ela já foi para outros empobrecidos de antanho.

Seguindo o arrazoado acima, mesmo observada em sua historicidade local, entende-se que a educação nunca deve ser compreendida desatrelada de sua formatação mais global. Entretanto, por questões de espaço e objetivo, o olhar neste texto estará voltado apenas para a educação das camadas mais empobrecidas do Sertão nordestino, a partir de Catingueira - PB. Como para todo o Brasil, levar-se-á em conta que a formação escolar para o sertanejo pobre esteve, historicamente, comprimida entre a utopia e a realidade da penúria material, do abandono político, do sofrimento e da migração etc. Apontar-se-á, no entanto, elencando algum sinal de esperança, que assim como à beira mar, a escola sertaneja vem se modificando, de dentro para fora e de fora para dentro, em decorrência, sobretudo, de ações trazidas pelas políticas públicas recentes. Se reconhecerá que mesmo contendo componentes ainda sombrios, como descasos para com trabalhadores(as) e para com os equipamentos públicos da educação, a escola sertaneja, como no restante do Brasil e do mundo, contém fragmentos de esperanças, se afirmando como contributo à quebra do ciclo de miserabilidade e pobreza que têm marcado aquela cidade e a região. Conclui-se, contudo, que estes são apontamentos iniciais e que muita coisa ainda carecerá de aprofundamentos.

\section{Algumas palavras sobre o campo da pesquisa}

A pesquisa de campo que alimenta este artigo foi realizada no Sertão da Paraíba, no Nordeste do Brasil, numa cidadezinha que fica encravada ao pé de uma montanha de pedras, e é conhecida pelo nome de Catingueira. Localiza-se a $360 \mathrm{~km}$ de João Pessoa, capital do Estado da Paraíba. Sua população ainda é bem pequena, não passando dos cinco mil habitantes, embora se diga que o mesmo tanto ou mais se encontra fora da cidade, em consequência da migração historicamente imposta à região. 
Pouco mais da metade de sua população reside em sua enorme zona rural. Contudo, mesmo na parte urbana não é muito fácil se estabelecer uma separação daquilo que seria estritamente rural. Ao amanhecer, sem nenhuma cerimônia circulam pela cidade cabritas, cavalos, porcos, bem como aves e outros animais de pequeno porte. Algumas famílias criam, no seu quintal, galinhas, patos ou outras aves domésticas.

Mesmo tendo lá outras religiosidades, como indicam a presença de 04 igrejas evangélicas e de 01 centro espírita, o grosso de sua população é católica e devota de São Sebastião, rememorando-o todo dia 20 de cada mês, tendo uma celebração muito pomposa, antecedida por uma novena, no dia 20 de janeiro de cada ano, data em que se festeja o dia do santo padroeiro municipal.

Em Catingueira não é possível estabelecer com clareza os critérios de diferenciação de classes na escala que vai da baixa, passando pela média até chegar à alta. Observa-se que, embora coexistam lá três elites - uma elite de tipo tradicional, marcada orgulhosamente pelo nome da família, uma elite econômica que sempre teve dinheiro ou que se enriqueceu recentemente por meio do comércio e/ou do entrelaçamento com a política e uma elite política, com bem pouca representação dos mais humildes - o grosso de sua gente é predominantemente pobre e assalariada. Cada família vive como pode, trabalhando na agricultura, no comércio, no serviço público, na pesca em açude, no empreender individual, na costura doméstica, na fabricação de artesanato, nos serviços autônomos, na construção civil. Além disso, algumas pessoas sustentam-se por meio de pensões, de aposentadorias e do dinheiro enviado pelos filhos que moram fora da cidade. Vive-se também do Programa Bolsa Família - PBF (PIRES \& SILVA JARDIM, 2014, SILVA, 2014; SANTOS \& SILVA, 2015), este último, embora irrisório, por ser uma renda fixa, tem ajudado bastante a população.

\section{Uma nota sobre o método nesta investigação}

Em pesquisa, o método é o caminho que o investigador escolhe para atingir seus objetivos acadêmicos. Neste trabalho adotou-se a abordagem etnográfica. Entende-se que a etnografia é descrição densa de uma determinada realidade experienciada, a qual, segundo Geertz (2008), busca compreender os cenários e os sentidos presentes nas teias relacionais humanas. A etnografia, segundo Ferreira (2014) é ainda uma tentativa de tradução da realidade investigada; essa tradução está, no caso desta pesquisa, para além do domínio da língua falada. De qualquer modo, a finalidade da etnografia é também explicar e interpretar o vivido em sua totalidade, sobretudo, a partir do entendimento que os sujeitos envolvidos nos 
fatos apresentam. É claro que o discurso de um pensador local não tem a obrigação de se nivelar àquele apresentado por um pesquisador e por seus autores. Mesmo assim, é importante não se extinguir da mente que as pessoas contatadas em uma pesquisa, a seu modo e baseando-se em seus saberes, segundo Brandão (2007, p. 18): “[...] têm categorias de interpretação da realidade como nós temos. As nossas não são nada mais, nada menos do que uma eruditização dessas categorias".

Seguindo a lógica da etnografia, nesta investigação já foram utilizadas técnicas e/ou instrumentos de coletas de dados tais como: observação participante (MALINOWSKI, 1922/1978), observação flutuante (PÉTONNET, 2008), observação em movimento (SILVA, 2014), fotografias, diário de campo, diário sonoro reflexivo, conversas informais, consulta a periódicos locais (Catingueira Oline e Portal Catingueira), entrevista não estruturada. Em parte esse artigo é resultado do uso de algumas dessas ferramentas, não todas ${ }^{4}$.

E mesmo que se esteja aqui tratando da educação e no último ano (2016) tenham sido entrevistados 07 idosos (pessoas entre 60 -80), 10 adultos (30-50 anos) e 12 jovens (16-25 anos), figurando nesta representação: 02 diretores(as), 05 professores(as), 02 parlamentares, 01 uma ex-vereadora, 01 secretária de educação e 01 ex-secretária de assistência Social, 01 líder sindical, 01 líder comunitário, 01 empresário, etc, este trabalho não aconteceu dentro dos muros das escolas do município. Todos os encontros com os participantes ocorreram no meio da rua, nas casas das pessoas, nas calçadas, nas praças, com informações nem sempre muito arrumadas ou procuradas. As entrevistas, quando gravadas, eram apresentadas aos entrevistados, ocasião em que novos esclarecimentos iam sendo acrescentados. Além desses elementos acima mencionados, têm-se convivido com alunos(as), pais e mães, crianças, jovens e adultos, com os quais se têm tido conversas, em mais de meia década de convívio, as quais, embora sumamente importantes, tornaram-se impossíveis de serem contadas/catalogadas. Ressalta-se, contudo, que as conversas informais também serviram bastante para que fosse possível a composição deste artigo.

Mesmo que as identidades dos participantes sejam preservadas ao longo do texto, todas as pessoas que foram colaboradoras têm conhecimento desta pesquisa no município, sobretudo, por conta das visitas regulares feitas desde 2012, com três idas por ano, totalizando um convívio de, no mínimo, 45 dias anuais. Na primeira ocasião, depois de uma semana de hospedagem em uma maternidade pública, foi alugada uma casa para um mês, nas demais ocasiões, já com amigos na cidade, foi possível a hospedagem em casa de moradores locais.

\footnotetext{
${ }^{4}$ Para evitar alongamentos nesse trabalho, remete-se o leitor ao texto do autor (SILVA, 2018), o qual detalha e aprofunda algumas das explicações aqui encetadas.
} 
Isso também serviu de ajuda para a entrada no mundo dos mais pobres, vendo-o de dentro, como sugere a etnografia. Embora membros de outras camadas sociais tenham sido entrevistados, o olhar deste artigo, como já dito acima, será focado nos mais empobrecidos.

\section{Apontando para alguns resultados reflexivos}

No espaço abaixo serão apresentados e comentados alguns dos resultados deste percurso investigativo.

\section{O sacrifício pela educação dos pobres no Sertão}

Catingueira tinha em 2016 aproximadamente 40 jovens fazendo formação universitária. Para isto se deslocavam, todos os dias, num percurso de 45 quilômetros, até a cidade de Patos - PB. Não estão incluídas nesse número as pessoas que fazem graduações no final de semana - na modalidade semipresencial, nem as que fazem formação via EAD Educação à Distância. Também não estão contadas as que, enquanto realizam formação superior, tendo famílias com alguma condição financeira melhor, são mantidas em Campina Grande - PB, João Pessoa - PB ou em outras cidades. Dos filhos do município, muitos jovens têm hoje graduação e pós-graduação, tendo entre os seus filhos especialistas, mestres e doutores. No primeiro nível não são poucos.

Pensando-se na leva de jovens que diariamente se desloca, enfrentando toda sorte adversa para estudar, tem-se a sensação de que num determinado momento da vida sertaneja as gerações mais velhas dos pobres começaram a entender que era imperativo algum 'sacrifício' para que seus filhos pudessem estudar e se formar. E das muitas conversas obtidas, observou-se que as gerações mais velhas descobriram nisso certo orgulho. "Meu filho se formou. Eu sou somente um roceiro. Foi muito difícil, porque a nossa família nunca teve posses", contou seu Valdomiro (65 anos) com os olhos em lágrimas. Os próprios jovens universitários reconhecem que não galgariam melhores espaços sem o esforço pessoal, muitos trabalham o dia inteiro e+ nem sempre têm tempo para tomar uma refeição antes de sair de casa e quando não têm dinheiro para o lanche só se alimentam quando retornam, depois da meia noite. Mas estes mesmos jovens entendem que seus estudos seriam impossibilitados sem a colaboração de suas famílias. "Minha mãe me ajuda a pagar a faculdade" (Claúdia, 22 anos). "Meu pai sempre que pode me dá dinheiro pra lanchar" (Rafael, 19 anos). "Quando eu desanimo, minha família cai em cima de mim" (Rafael, 26 anos). "Minha sorte nesse curso foi 
meu irmão. Ele pagou minha faculdade toda, eu não teria condições" (Cícera, 34 anos). Essas são algumas das expressões que revelam a presença da família em várias situações.

A referência a estes dados não quer dizer que houve um tempo em que as gerações mais velhas não se sacrificavam pelas mais novas. Todas as gerações, de alguma forma e nalguma direção, se privaram para que as mais novas fossem melhores beneficiadas. Até hoje é assim e os relatos trazidos pela memória sertaneja comprovam tal fato. Há na cidade relatos de famílias que se obrigaram a abandonar Catingueira, especialmente, para que os filhos pudessem ter acesso ao estudo. E se algumas gerações não fizeram isso na direção do estudo formal foi porque nem os pequenos sacrifícios eram possíveis, dada a penúria a que estavam submetidas as famílias mais empobrecidas da região. Provavelmente, naquele momento, no universo das gerações mais velhas estava apenas a responsabilidade pela sobrevivência material. Aliás, uma noção que fosse muito discrepante dificilmente chegaria a ser sonhada, aspirada, dada a dureza descrita daquela realidade. Logo esse movimento também é novo. Nas sociedades mais antigas, "[...] as experiências coincidiam com as expectativas: quem nascia pobre morria pobre; quem nascia iletrado morria iletrado. Agora não: quem nasce pobre pode morrer rico, e quem nasce em uma família de iletrados pode morrer como médico ou doutor" (SANTOS, 2015, p. 18). Nas expectativas contemporâneas pode-se até ter algum exagero, mas, o valor que está sendo impetrado à escola e à educação formal, praticamente, não existia nem podia existir numa família marcadamente pobre, cujo lugar social de cada membro estava dado a priori. E onde existia a escola como valor, este era um valor ilhado. Não apenas porque não era um conhecimento 'necessário' ao mundo do roçado, mas porque era muito difícil a ele se ter algum acesso. É preciso não esquecer que há pouco mais de meio século o Nordeste inteiro ainda era acentuadamente rural.

A importância dessa noção de sacrifício pela educação ganha mais clareza quando se pode analisar a pobreza a que muitas gerações estiveram submetidas. Seu Antonio, (50 anos) relatou que, em seu tempo de menino, quando se ia para uma festa, por exemplo, e isso era muito raro, porque geralmente não se tinha indumentária e nem sempre se conseguia uma de empréstimo, "Não era pra se divertir. Era apenas para assistir a uma missa". "Talvez ao final, se tivesse muita sorte, seria possível comer um pão doce com caldo de cana ou um pedaço de pão com um caneco de refresco" (Antonio, 50 anos). Se alguém propusesse isso às crianças de hoje nem seria compreendido. Seria, como disse seu Mario (72 anos), "Uma conversa de ET". Nada de luxo, nada de vaidade ou veleidades, por mais ínfimas que fossem. Com o que se poderia sonhar? 
$\mathrm{Na}$ ambiência dos pobres sertanejos, as crianças não podiam ter necessidades, porque todas as carências das gerações mais velhas foram silenciadas. Dona Francisca (70 anos) revelou que sua infância, bem como a de seus 12 irmãos, "Foi toda no cabo da enxada". Ela acrescenta ainda, com certa tristeza nos olhos: "Se for pecado, Deus me perdoe, mas a única coisa que eu tenho inveja na vida é de quem pega um pedaço de papel e ler. Do resto, não tenho inveja de nada neste mundo". Aliás, nos muitos relatos a que se teve acesso, as gerações das pessoas mais velhas, usando-se alguns dos critérios contemporâneos, tiveram todas as suas necessidades básicas ou negadas ou não garantidas.

\section{"Vá estudar para virar gente"}

Na Catingueira sertaneja pode-se dizer que a educação hoje é um valor inquestionável para todas as gerações mais velhas. E do que foi percebido no imaginário de muitas famílias, naquele pedaço do Nordeste do Brasil, o estudo parece ser o único caminho para que o filho de um pobre possa conquistar alguma mobilidade na ainda dura estrutura social do país e da região. Por isso, a maioria dos homens e mulheres pobres do Sertão certamente já vêm escutando há algumas décadas: "Vá estudar pra virar gente". Como relata Regina Celi Delfino da Silva (2016, p. 99): "Minha mãe, apesar de não escolarizada, via na escola uma oportunidade de progressão na vida; nos dizeres dela, "para ser gente"”.

Para uma pessoa desacostumada com esse linguajar, expressão dessa natureza pode soar, de certa maneira, meio ofensiva. Não é que os pobres não gozem do estatuto universal das pessoas humanas. Não quer dizer também que sejam considerados bichos. Os filhos e filhas de um casal sertanejo pobre não são comparados ao cãozinho vira-lata que, por ventura, rodeia a sua casa. Não se trata disso.

Estudar para virar gente é uma expressão que precisa ser compreendida e interpretada em sua historicidade. Ao que tudo indica, nela está expressa uma crítica ao sistema econômico e político que estabelece um fosso abissal entre os que têm dinheiro e aqueles que muito pouco ou quase nada possuem. Ela aponta para a ideologia que diferencia ricos e pobres, indicando que um é 'o bichão graúdo', 'o endinheirado', 'o que enricou', 'o homem de posses', 'o dono das terras e dos rebanhos', que se assenta nos primeiros lugares, que goza de uma vida confortável, que sempre mandou e desmandou no destino de muitos. Ela revela também que aquele que carece estudar para virar gente é quase um 'João-Ninguém' da vida e que, sem o estudo, irá ter, quando muito, apenas o próprio nome a zelar, o sol e céu sobre sua 
cabeça. Nessa expressão está, sobretudo, a denúncia da vida penível que, ao longo dos séculos, o homem simples e sua família têm levado no sertão nordestino.

Porém, contraditoriamente, no 'vá estudar para virar gente' está abscôndita a esperança e o sonho dos mais pobres. É claro que ao dizer isso, há que se destacar o quanto é referenciado e até reverenciado o jovem formado no município. "Ele se formou em Educação Física", contou D. Marta (63 anos), acrescentando também: "Dos meus 08 filhos, esse foi o único que deu pra gente na vida". Os outros não eram vagabundos ou maus elementos, apenas não puderam estudar...

Observou-se que muitas das pessoas que insistiam para que seus filhos não se atrasassem para a escola eram oriundas de genitores analfabetos e muitas delas mal assinavam seu próprio nome. Em que se baseavam os pobres para compreender e indicar que a escola deveria ser o caminho melhor e preferível para seus filhos? O "vá estudar pra virar gente" não estava se baseando nos ricos. Ricos escolados eles conheceram aos montes ao longo de toda sua vida e de diversas gerações. Sem dúvida, existe no "vá estudar para virar gente" uma leitura da realidade concreta, mas essa leitura é feita de esperança, de sonho, de afeto, mas também de possibilidade. Os pobres parecem enxergar hoje uma possibilidade não existente no passado.

Está claro que os pais trabalhadores camponeses, por exemplo, sabem que não podem deixar terras, rebanhos ou fazendas para sua prole. Muitos deles não têm um taco de terra para cultivar. Muitas vezes, mesmo morando na cidade, não têm como nela se sustentar; quando não encontram vaga nos serviços públicos, como concursados ou contratados, vivem trabalhando como serventes de pedreiros ou como simples trabalhadores rurais alugados. E mesmo aqueles que têm um terreno próprio para plantio, este é geralmente tão pequeno que não chega a ser considerado com uma verdadeira propriedade, daquela que, ficando como herança, ajudaria e muito na condição e no status dos filhos.

Assim, o estudo vai se perfilando no imaginário popular sertanejo como um caminho sem volta. "O pobre só pode dar o caminho da escola ao seu filho", frase de seu Agenor (83 anos). Naquele universo, ao longo de mais de meia década, não foi possível encontrar nenhum adulto que não reconhecesse o valor da escola em Catingueira, e, se tal pessoa existe, é provável que sinta vergonha de manifestar esse pensamento naquela ambiência municipal.

\section{Afirmando a importância da escola e da educação através das gerações}


Este trabalho, para voltar ao tempo, teve de se valer da memória daqueles e daquelas que vivenciaram a educação na região sertaneja em sua infância. É bem verdade que essa percepção é lida hoje de forma muito mais elaborada, cotejada pela vivência do tempo presente. Os mais velhos olham seu passado, com saudade, mas também com algum aperto no coração, não com mágoa, mas de certo com uma pequena e sutil revolta. Há, inclusive, o argumento de que hoje só não estuda quem não quer. Aliás, o grito pela qualidade do ensino não existe nos meios populares adultos e idosos catingueirenses. Ninguém das gerações mais velhas critica a escola. A escola é um bem social. Ponto. Para quem não teve nada ou teve tão pouco...

Ainda na primeira pesquisa de campo realizada, ouviu-se de seu Júlio (80 anos), que quando ele era criança nem escola oficial existia no município. É importante lembrar que a principal e mais antiga escola da cidade completou 50 anos em $2016^{5}$.

Na segunda pesquisa, uma senhora, D. Margarida (74 anos), relatou que estudou muito pouco, já moça, mesmo assim contrariando seu pai, para quem meninas só deveriam ficar na escola até aprender a escrever o nome. Se ficassem mais tempo aprendiam a escrever 'cartinhas para namorados'.

Um dos entrevistados indicou que a escola de sua infância, de tão insípida, não conseguiu acolhê-lo. Ele ia para a escola apenas porque queria comer. Em seu julgamento, seu grau de pobreza era tão grande ao ponto de incapacitá-lo ao aprendizado formal: "Nós éramos tipo favelados. A escola não significava nada pra mim", Damião, (47 anos). De qualquer forma não se tratava dum sujeito sem inteligência, visto que hoje, depois das voltas da vida, conseguiu completar uma formação pós-graduada.

Um outro cidadão, Renato (37 anos), revelou que em seu tempo de estudo a escola catingueirense não tinha atrativo nenhum. Era caótica e completamente desestimulante. Em sua discrição, a professora assentava a tarefa na lousa, depois deixava as crianças na sala e saía para fumar. Seus colegas chegavam e chamavam-no para jogar bola, o que lhe parecia muito mais interessante. Quando a professora voltava à sala, ela sequer dava fé de que ele tinha ido embora. Resultado, embora de uma inteligência artística formidável, não completou seu ensino fundamental, do que se ressente, logicamente, contando que tem perdido muitas oportunidades por não ter estudado. Esse é apenas um caso.

\footnotetext{
${ }^{5}$ Para que o texto não seja esticado em comentários, remete-se o interessado leitor à notícia da fundação da Escola Inácio da Catingueira no Blog da própria Escola, disponível em: http://inaciodacatingueira.blogspot.com.br/p/sobre-escola.html. E a notícia da comemoração do cinquentenário no Portal Catingueira, disponível em: http://www.portalcatingueira.com.br/jubileu-de-ouro-gincana-marca-os50-anos-da-escola-inacio-da-catingueira/.
} 
A opção pela escola para os idosos, aqui pessoas acima de 60 anos, e para os adultos que estão no entorno do 35-50 anos estava bastante comprimida pela carga da realidade e era difícil sonhar com uma possibilidade que se colocasse para além da obtenção do próprio sustento material. A Angélica (40 anos) disse que a escola de seu tempo era uma realidade já firmada no município, mais ou menos comum e valorizada na opinião de sua família, mas um estudo completo era muito pouco possível para a maioria dos meninos e meninas de sua geração. Ela chegou até à quinta série. Depois disso teve que largar os estudos para aprender uma profissão que lhe desse algum dinheiro, sendo hoje uma importante costureira.

A situação começa mesmo a virar naquela geração que está hoje perto dos 30 anos. As pessoas de 20 aos 30anos, assim como as mais velhas, em Catingueira, acreditam que a escola é o único caminho possível para o sucesso, para emancipação humana, para a conquista de um bom trabalho e de um bom salário. Para Tânia (26 anos) a escola sempre foi um valor, tanto é que ela chegou a completar a sua formação superior, sem ser obrigada a trabalhar antes disso. Hoje é funcionária pública concursada, conquista da qual se orgulha, porque facilitou-lhe a permanência naquele município do sertão.

Há que se pensar que essa foi a geração que cresceu à sombra do ECA. Não se sabe se foi somente o ECA. De certo, as políticas públicas começaram a se expandir bastante depois da redemocratização do país e, embora não tenha ainda sido possível debelar o gigante déficit social, não é possível pensar que o conjunto de ações derivadas delas não fez algum efeito, sobretudo para os mais longínquos rincões deste país.

É claro que nos últimos 30 anos o intercâmbio dos jovens começou a se intensificar. Há pessoas da cidade de Catingueira que tiveram a oportunidade de estudar em João Pessoa, fizeram faculdade e puderam retornar ao município como professores ou técnicos da área de saúde, por exemplo. Mesmo com toda dificuldade para conseguir, alguns jovens pobres disseram ter estudado porque conseguiram bolsa de estudos pagas pelos cofres públicos. É interessante pontuar que, mesmo sem o revelar expressamente, estes jovens em suas falas apontam para a existência de uma política de governo que se ampliou tanto na construção de universidades públicas na região quanto na implementação do acesso ao crédito educativo em faculdades privadas nas últimas décadas. E há quem isso chegue a destacar: "Dou graças a Deus! E peço que Deus abençoe o presidente Lula. Se não fosse ele eu não tinha como pagar a minha faculdade" (Lemuel, 27 anos).

Possivelmente foi olhando para os filhos das camadas sociais pobres que conseguiram ascensão escolar, como já mencionado anteriormente, que famílias sertanejas começaram a 
enxergar outra possibilidade, ou melhor, puderam ter o mínimo de certeza de que outra possibilidade existiria para seus filhos. Não estavam se baseando nos ricos. Aliás, nem ouviuse sequer menção de que os pobres estariam ou tenham se inspirado nas camadas mais abastardas do município. Os filhos dos ricos eles sempre viram estudar, na opinião de Justo (29 anos): "Sempre se deram bem, sempre ocupam os principais postos de trabalho, quando aqui ficam. Mas, na maioria das vezes, nem ficam na região”.

Importante para o pobre, interpreta-se aqui à revelia, foi ver o pobre formado voltar. Nunca foram muitos. Mas já é possível. E esse movimento é relativamente recente nas paragens sertanejas. Então, esse entendimento parece ser muito mais intuição construída a partir da experiência de rapazes e moças pobres que conseguiram estudar, se formar e voltar para o município como letrados.

É importante lembrar que entre os pobres catingueirenses existe uma escala bastante variável de pobreza e uma família pobre nunca é igual a outra. Uma família pobre que tem dois salários mínimos não se compara a uma família que vive da aposentadoria de um idoso ou a uma que vive apenas do Programa Bolsa Família.

\section{O Programa Bolsa Família: importante atravessador da escola sertaneja contemporânea}

Em relação ao processo educacional, o entendimento mais compartilhado em Catingueira é o de que tudo se encontra muito melhor do que no passado. "O governo dá o carro, dá a escola e até paga para os estudantes ficarem na escola. Quando eu era criança nem escola existia. Tinha a casa da professora, mas somente quem podia pagar é que ia estudar" (SILVA \& PIRES, 2012, p. 8), foi um senhor de 80 anos quem disse isso. Diferenciando-se um pouco mais dessa imagem do passado, a realidade escolar de Catingueira tem mesmo se modificado.

Alguns pensadores locais se orgulham de que toda criança em idade escolar encontra-se matriculada. Aliás, um dos problemas graves da educação do 'passado recente', era o abandono da escola pelo alunado, que a literatura especializada descreveu como "evasão escolar" e atualmente tem preferido chamar de "infrequência" (LEÃO, 2015). Ela encobria uma enorme onda de dificuldades, entre as quais: a não aprendizagem, a não alfabetização na idade certa, a distorção idade série, a reprodução de comportamento escolar inadequado, a indisciplina, o analfabetismo, a produção do fracasso escolar. A evasão escondia, sob uma névoa política bastante grosseira, questões sociais, econômicas, culturais, teóricas e metodológicas. As crianças pobres eram arrancadas das escolas por inúmeros motivos. Muitas 
precisavam ajudar seus pais no trabalho do roçado, nos empregos domésticos, na criação dos irmãos menores, assumindo tarefas da própria casa enquanto pais e mães trabalhavam fora etc. Mas será que as crianças nunca abandonavam a escola também por questões que diziam respeito à própria escola? Há que se concordar com a afirmativa de Leão (2015, p. 3): "Para mim, o problema não é evasão, é expulsão. As escolas expulsam muito mais do que dela se evadem os alunos". Em Catingueira e no resto do Brasil, uma vez que a criança se evadia, a pedagogia, em certo sentido, se sentindo aliviada por nem sempre saber o que fazer e por estar assoberbada por incomensuráveis motivos, não se dava ao trabalho de tentar compreender se o problema tinha sido por causas externas ou por razões de sua própria cozinha, se estavam presente questões de aprendizagem e/ou de ensinagem, se a didática teria tido possibilidade diferente em outra situação. A evasão escolar ocultava ainda a defasagem da infraestrutura escolar, o mal cuidado, a carência de material, o sucateamento dos equipamentos, o preparo pouco do professorado etc. Na maioria dos casos de fracasso não era sequer possível saber se a criança chegava a ter alguma dificuldade ou mesmo uma deficiência intelectual. Aliás, na Paraíba toda, o cuidado com a criança que apresenta deficiência intelectual é uma preocupação apenas dos últimos 25 anos, com o trabalho da Fundação Centro Integrado de Apoio ao Portador de Deficiência - FUNAD ${ }^{6}$.

Mesmo que a escola tenha alcançado uma enorme valorização ao longo da história nacional, sobretudo com a redemocratização, com o advento das políticas públicas inspiradas no ECA, estabelecidas na LDB, a retirada abrupta da criança dos quadros escolares só se acabou em Catingueira na última década. E aquilo que era valor absoluto nas famílias abastardas passou a ser agora constatado inclusive nas famílias com baixíssima renda, naquelas que vivem apenas do Programa Bolsa Família.

Essa observação embora já conhecida dos trabalhos feitos em Catingueira, surgiu de modo bastante espontâneo na fala de uma antiga professora, ex-diretora e ex-secretária de educação entrevistada, a qual foi conclusiva ao dizer que a evasão escolar em Catingueira não era mais um problema municipal. Quando perguntada a que se devia tal fenômeno, ela retrucou: "O Bolsa Família zerou a evasão escolar no sertão" (SILVA, SANTOS \& NOGUEIRA, 2017). Embora de alcance inseguro e ainda limitado em muitos aspectos, sob vários questionamentos, aqui e acolá sob ameaça, sobretudo, por razões político-partidárias, é importante reconhecer que essa solução veio através de uma política pública. Não foi somente

\footnotetext{
${ }^{6}$ A FUNAD atende, como política pública, em nome do governo do Estado da Paraíba, oferecendo serviços em 04 especialidades: Deficiência Física, Deficiência Visual, Deficiência Auditiva e Deficiência Intelectual. Na última década encampou também atendimento à pessoa autista.
} 
a redemocratização, a Constituição de 1988, a LDB, o ECA ou o Programa de Erradicação do Trabalho Infantil - PETI, mesmo que não se negue a contribuição dessas já antigas ferramentas das transformações nacionais.

Contudo, apesar das crianças terem lá uma atenção especial, há que se mostrar que o Bolsa Família não foi criado para elas. Como reflete Pires (2015, p. 208): “Como um programa para a família, os benefícios diretos do programa acabam por resvalar nas crianças, beneficiando-as de maneira lateral”. Não se justifica julgar aqui se essa lateralidade é dada na imposição de uma frequência escolar, no controle da família pobre pelo Estado, numa política eleitoreira, etc. Como pensam Santos, Silva e Ferreira (2016, p. 6): “A retirada da criança da situação de trabalho pela condicionalidade educacional, através da exigência de uma frequência mínima de $85 \%$ da criança na escola, ajuda tanto a criança quanto a escola". Ajuda e vai além, ela exige novas respostas da instituição escolar. Com uma frequência de $85 \%$ dificilmente um professor poderá justificar a não alfabetização de uma criança nas séries iniciais.

Os professores de Catingueira percebem isso. Muitos até cobram das crianças.

Outro dado importante a ser registrado é que as famílias atingidas pelo Programa Bolsa Família são geralmente aquelas mais empobrecidas. E essa ação política, em muitos casos, acaba melhorando a autoestima das crianças, dando a elas uma melhor condição financeira, de certo modo aproximando-as de uma possível igualdade entre os seus pares. Em Catingueira, conforme Pires, Falcão e Silva (2014, p. 161): "Isso era visto na escola, por exemplo, na exibição de materiais escolares, roupas (uniformes), calçados novos e no acesso à merenda comprada". Além do mais, como se tem vindo a constatar, algumas pesquisas desenvolvidas no referido município têm destacado a importância e eficácia dessa política pública não somente para o aprimoramento da frequência escolar, mas, sobretudo, para a possibilidade da quebra do ciclo geracional da pobreza (PIRES \& SILVA JARDIM, 2014; PIRES, FALCÃO \& SILVA, 2014; SANTOS \& PIRES 2013).

\section{Ainda alguns pontos para finalizar}

$\mathrm{Na}$ verdade, a escola mudou muito no Sertão e em Catingueira. Mudou em número e também em sua qualificação profissional. Antes ia-se à casa da professora, quando se podia pagar, depois ia-se à escola pública, desde que se pudesse comprar fardamento e material escolar completo. Hoje o município dispõe aos filhos das famílias pobres ao menos duas grandes escolas públicas, uma municipal e uma estadual, uma oferecendo ensino fundamental 
e a outra, o ensino médio ${ }^{7}$. Além disso, um número significativo já emenda no ensino superior.

Embora não disponha de uma estrutura invejável, a escola pública catingueirense, na opinião dos idosos e adultos, seus observadores locais, representa um valor inestimável. Para muitos membros das gerações de idosos pobres, a educação formal na infância foi apenas uma impossibilidade, considerando que o seu acesso era quase um disparate, um desperdício de tempo. Em alguns casos essa lacuna foi corrigida no avançar da idade, situação de Seu Paulo, aos 70 anos, quando muito orgulhosamente completou seu Ensino Médio, por meio de um curso supletivo, tendo direito a festa de formatura e tudo. Para as gerações que atravessam hoje os 40 e 50 anos, em sua infância, a educação foi apenas um valor comprimido entre o sonho e a realidade. A permanência era completamente desanimadora. E o sucesso era possivelmente um milagre. Mas para as novas gerações, para a geração que cresceu com o ECA, por exemplo, a educação já foi uma possibilidade e para a geração do Bolsa Família, como mostram Pires e Silva Jardim (2014), muito mais do que uma possibilidade, a educação se tornou uma realidade obrigatória.

Está claro que embora esteja reconhecida como melhor pelas gerações catingueirenses mais adultas, mais acessível, com mais garantia da permanência das crianças, a escola sertaneja ainda não resolveu muitas de suas questões. Ainda funciona em precariedade estrutural e econômica, com problemas relacionados à atualização tecnológica, à valorização salarial dos professores, tendo dificuldades relativas à quadra de esportes, à merenda, etc. No entanto, é preciso fazer alguma ressalva. Para Pires (2015, p. 292). “[...] mesmo precária como é, devemos ter em mente que, para a maioria da população, esta é a primeira geração a ter acesso ao ensino básico regular". Vale lembrar que no passado, não muito distante, após o término do ensino fundamental, os estudantes tinham de se aventurar indo para Patos - PB, através de carona. Por isso, muitos dos que não entravam nos quadros da evasão não passavam do ensino fundamental.

É bem verdade que ainda não é fácil montar um quadro pedagógico naquelas paragens. Talvez por isso o diretor de escola tenha contado, todo orgulhoso, que sua equipe estava completa. O único profissional que faltava era o professor de filosofia. A solução foi convidar o padre da cidade para ministrar as aulas, uma vez que ele era o único profissional que tinha o referido curso. É interessante observar que, dentro da conjuntura municipal, os professores do

\footnotetext{
${ }^{7}$ Os filhos das elites tradicionais, econômicas e políticas catingueirenses não estudam no município. As famílias fretam transportes particulares que os levam a Patos - PB, onde frequentam colégios particulares.
} 
Sertão tudo fazem para o aprimoramento da inteligência na região. Todos têm graduação concluída ou em andamento. A maioria tem algum curso de especialização.

Contudo, depois de ter resolvido o problema da evasão, a escola sertaneja parece encostada contra a parede. Começa a surgir nela a constatação de que, ao contrário dos pais e avós, os adolescentes contemporâneos se encontram desmotivados. Por que? É um elemento que carece ser mais detalhado em pesquisas posteriores. Além disso, pensa-se que será preciso encurralar as elites municipais para decidir, junto com os pobres, se a escola vai educar jovens para viver no Sertão ou para a migração. Talvez aí esteja a razão do desânimo juvenil. Depois disso, ela precisa responder a questões sobre como, de que forma e pra que educar, que conteúdos precisam ser selecionados...

\title{
LA ESCUELA Y LOS POBRES EN LA REGIÓN SEMIÁRIDA DEL NORESTE DE BRASIL: CONSIDERACIONES ETNOGRÁFICAS DE CATINGUEIRA - PB
}

\section{RESUMEN}

En este artículo, a partir de una investigación etnográfica, elaborada en Catingueira - PB, mi objetivo es reflexionar sobre la importancia que la escuela fue conquistando a través de las generaciones en el semiárido del Nordeste de Brasil. Señalaré que la escuela es hoy una de las instituciones más importantes en las familias pobres de la región. Quedará resaltado que el deseo de una educación fue, durante muchas generaciones, asfixiado entre el sueño y la dura realidad material del trabajo infantil, de la negligencia política, del sufrimiento y de la migración... Señalo, sin embargo, que la escuela en la región semiárida se ha modificado, de dentro a fuera y de fuera a dentro, resultado de los recursos interpuestos por las políticas públicas. Voy a mostrar que aún contenga componentes oscuros, como la negligencia hacia los trabajadores de la educación pública, la escuela tiene todavía fragmentos de esperanzas, estableciéndose como una contribución para romper el ciclo de la miseria que tiene marcado la ciudad y la región.

Palabras clave: Escuela, Semiárido, Etnografía.

\section{THE SCHOOL AND THE POOR IN THE SEMIARID OF NORTHEAST FROM BRAZIL: ETHNOGRAPHIC CONSIDERATIONS FROM CATINGUEIRA - PB}

\begin{abstract}
In this article, based on an ethnographic research, elaborated in Catingueira - PB, aims to reflect on the importance that the school was conquering through the generations in the semiarid of Northeast from Brazil. Will indicate that the school is today one of the most important institutions in poor families in the region. Show that desire of an education was, for many generations, compressed between the dream and the reality of material hardship, early labor, political neglect, suffering and migration... I point out, however, that the school in the
\end{abstract}


semiarid has been modified, from inside to outside and from outside to inside, as a result of actions brought by public policies. I testify that even containing still no goods components like negligence towards workers and to the public equipment of education, the school has still fragments of hopes, establishing itself as a contribution to break the cycle of misery that have marked this city and the region.

Keywords: School; Semiarid; Ethnography.

\section{REFERÊNCIAS}

BRANDÃO, Carlos R. Reflexões sobre como fazer trabalho de campo. Cultura e Sociedade, V 10, No 1, Jan/Jun. p. 11-27, 2007. DOI: https://doi.org/10.5216/sec.v10i1.1719.

CASTRO, Lúcia. R. O futuro da infância e outros escritos. Rio de Janeiro: 7 Letras, 2013.

CAMPOS, H. R.; LEAL, Z. F. R. G. \& FACCI, M. G. D. Direito à educação, formação do adolescente e adoecimento docente no Estado capitalista. Revista Educação em Questão, Natal, v. 54, n. 40, p. 205-230, jan./abr. 2016. DOI: 10.5935/1981-1802.20160009.

FERREIRA. Alice M. A. O paradigma da descrição na tradução etnográfica: Levi-Strauss tradutor em Tristes Tropiques. Acta Scientiarum. Language and Culture Maringá, v. 36, n. 4, p. 383-393, Oct.-Dec. 2014. DOI: 10.4025/actascilangcult.v36i4.23837.

FREIRE, Paulo. (2000). Pedagogia da Indignação: Cartas Pedagógicas e outros Escritos. São Paulo: Editora UNESP.

GEERTZ, Clifford. "Uma descrição densa: por uma teoria interpretativa da cultura". In: A interpretação das Culturas. $1^{\mathrm{a}}$ ed. 13 ${ }^{\mathrm{a}}$ reimp. Rio de Janeiro, RJ: LTC, 2008.

LEÃO, Núbia M. M. O índice de evasão escolar na escola estadual Ernesto Panafor. Lat. Am. J. Sci. Educ. 1, 12054, $2015 . \quad$ Disponível em: http://www.lajse.org/may15/12054_Menezes.pdf. Acesso em 12 de dez. 2017.

MALINOWSKI, B. Argonautas do Pacífico Ocidental: Um relato do empreendimento e da aventura dos nativos nos arquipélagos da Nova Guiné Malinésia. (A. P. Carr \& L. P. C. Mendonça Trad.). 2a ed. São Paulo: Abril Cultural, 1978.

MÉSZÁROS, István. A Educação para além do Capital. (I. Tavares trad.) $2^{a}$ ed. São Paulo Boitempo, 2012.

PÉTONNET, Colette. Observação Flutuante: o exemplo de um cemitério parisiense. Antropolítica. Niterói, n. 25, p. 99-111, 2. Sem, 2008. Disponível em: http://www.uff.br/antropolitica/revistasantropoliticas/revista_antropolitica_25.pdf. Acesso em 12 de dez. 2017. 
PIRES, F. F; SILVA JARDIM, G. A. Geração Bolsa Família: educação, trabalho infantil e consumo na casa sertaneja (Catingueira/PB). Revista Brasileira de Ciências Sociais (Impresso), v. 29, p. 99-112, 2014.

Alimentando a família através do estudo: Programa Bolsa Família e as crianças no Nordeste do Brasil. In FRANCH, Mónica; ANDRADE, Maristela; AMORIM, Lara (Orgs.). Antropologia em novos campos de atuação: debates e tensões. João Pessoa: Mídia Gráfica e Editora, 2015.

; FALCÃO, Cristiane. R; SILVA, Antonio L. O Bolsa Família é Direito das Crianças: Participação Social infantil no Semiárido Nordestino. Teoria \& Sociedade, $n^{\circ} 22.1$ - janeirojunho, 2014.

Disponível

em:

http://www.fafich.ufmg.br/revistasociedade/index.php/rts/article/view/142. Acesso em 12 de dez. 2017.

SANTOS, Boaventura Sousa. Renovar a Teoria Crítica e reinventar a emancipação humana. São Paulo: Boitempo Editorial, 2015.

SANTOS, Patrícia O. S; PIRES, Flávia F. As crianças do Programa Bolsa Família e a Condicionalidade Escolar: uma análise antropológica da relação das crianças beneficiadas com o PBF. In: Anais da IV Reunião Equatorial de Antropologia e XIII Reunião de Antropólogos do Norte e Nordeste. Fortaleza 04 a 07 de agosto, 2013.

; SILVA, Antonio L. A cidade dos adultos ocupada pelas crianças: A ressignificação infantil dos espaços urbanos a partir de Catingueira - Paraíba. Política \& Trabalho - Revista de Ciências Sociais, nº 43, Julho/Dezembro, p. 167-184, 2015.

; SILVA, Antonio L; FERREIRA; Diana. C. "Fora de casa o único serviço que a gente faz é bagunçar": diferenças geracionais e contribuições de uma política pública para a agência das crianças. In: Anais Eletrônicos da 30ª RBA. UFPB, João Pessoa, 2016.

SILVA, Antonio L; PIRES, Flávia F. A criança e o ECA na pequena Catingueira paraibana: Direitos reivindicados, direitos conquistados? In: Anais da 28 ${ }^{\mathbf{a}}$ RBA, São Paulo, Brasil, 02 e 05 de julho, 2012.

Agonias dum pesquisador numa abordagem envolvendo crianças: reflexões advindas de Catingueira - PB. Revista de Psicologia da UNESP 13(1), 2014. Disponível em: http://pepsic.bvsalud.org/pdf/revpsico/v13n1/a07.pdf. Acesso em 12 de dez. 2017.

SANTOS, Patrícia O. S.; NOGUEIRA, Christina G. M. "O Programa Bolsa Família zerou a Evasão Escolar no Sertão": Uma Reflexão a partir de Catingueira - PB. In: Anais do IV CONEDU, João Pessoa, 15 a 18 de novembro, 2017. 
SILVA, Regina C. D. Estudar "para ser gente”: O móbil e as primeiras experiências escolares. Revista Lugares de Educação [RLE], Bananeiras-PB, v. 6, n. 13, p. 97 -102, Edição Especial, Nov. 2016. O método etnográfico: uma reflexão a partir de Catingueira - PB. PRACS: Revista Eletrônica de Humanidades do Curso de Ciências Sociais da UNIFAP, Macapá, v. 11, n. 2, p. 191-209, jul./dez. 2018. DOI: 10.18468/pracs.2018v11n2.p191-209.

\section{Sobre o autor}

Antonio Luiz da Silva é doutoro em Psicologia pela Universidade Federal do Rio Grande do Norte (UFRN). Mestre em Antropologia pela Universidade Federal da Paraíba (UFPB). Especialização em Gestão Escolar na FAK-CE e licenciatura e formação em Psicologia, ambas pela Universidade Estadual da Paraíba (UEPB). Endereço eletrônico: tonlusi@hotmail.com 